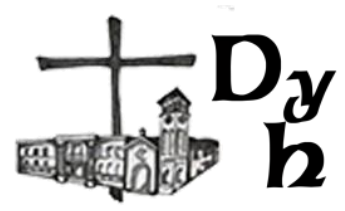

La cultura de la paz desde las perspectivas de las encíclicas Laudato si' y Fratelli tutti

Dios y el hombre, vol. 5, n. 1, e073, 2021

ISSN 2618-2858 - https://doi.org/10.24215/26182858e073

https://revistas.unlp.edu.ar/DyH/index

Cátedra libre de pensamiento cristiano - UNLP

Seminario Mayor San José

La Plata, Buenos Aires, Argentina

\title{
LA CULTURA DE PAZ \\ DESDE LAS PERSPECTIVAS DE LAS ENCÍCLICAS LAUDATO SI’Y FRATELLI TUTTI
}

\author{
The Culture of Peace \\ from the Perspectives of the Encyclics Laudato Si'and Fratelli Tutti
}

Mario Di Giacomo

madigiac@ucab.edu.ve

Universidad Católica Andrés Bello - Caracas - Venezuela

\begin{abstract}
Resumen
Este trabajo analiza los recursos teóricos que emplean Laudato si' y Fratelli tutti para consolidar una ética cósmica comprometida con la totalidad de la creación y con las deudas generacionales, así como una fraternidad universal que descree de las dimensiones cercano-lejano, pues el sufrimiento hace de lo infinitamente lejano algo profundamente cercano. La aspiración, difícil, de ambas es procurar un llamado a la paz entre los hombres, buscando lo que hay de común entre ellos, superando los muros que los separan gracias a ideologías arraigadas en el conflicto, en el temor y la segregación del desconocido. Metodológicamente el artículo intentará mantenerse más acá de los límites confesionales, para así extraer la savia propiamente racional de los argumentos. No deseo llamar a esto "ateísmo metodológico", pero sí "prudencia metódica", para, respetando aún ambas dimensiones, mantenernos en ésa en que la racionalidad marca las normas del discurso. El método a seguir es analítico-sintético: los documentos revisados se examinan de manera hermenéutica, propia de la tradición humanística, se confutan posiciones teóricas y se establecen conclusiones provisionales cercanas a los documentos pontificios analizados.
\end{abstract}

Palabras clave: Cultura de paz, ética cósmica, Casa Común, ética intergeneracional, fraternidad universal, amistad social

Abstract

This work analyzes the resources used by the encyclicals Laudato si' and Fratelli tutti to consolidate a cosmic ethic committed to the totality of creation and to generational debts, as well as a universal brotherhood that does not believe in the dimensions close-far away, because suffering makes the infinitely far something deeply close. The difficult aspiration of both is to seek a call for peace among men, seeking what is in common between them, overcoming the walls that separate them thanks to ideologies rooted in conflict, fear and the segregation of the unknown. Methodologically, the article will try to stay beyond the confessional limits, in order to extract the properly rational sap of the arguments. I do not wish to call this "methodological atheism", but I do want to call this "methodical prudence", in order, while still respecting both dimensions, keeping ourselves in that in which rationality sets the norms of discourse. The method to be followed is analytical-synthetic: the documents reviewed are examined in a hermeneutic manner, typical of the humanistic tradition, certain theoretical positions are confuted and provisional conclusions are drawn close to the papal documents analyzed.

Keywords: Culture of Peace, Cosmic Ethics, Common House, Intergenerational Ethics, Universal Brotherhood, Social Friendship

Recibido: $18 / 03 / 2021$

Aceptado: 04/05/2021

Publicado: 12/07/2021 


\section{Introducción: Futuro y pasado redimidos desde el presente}

Texto sensible y provocador, Laudato si' hace énfasis en las críticas realizadas a un tipo de progreso incapaz de mirar hacia el pasado y el futuro, por eso, puede definirse como una ética de carácter global, una ética planetaria de la Casa Común, teniendo en cuenta tanto el legado del pasado, como lo que habrán de heredar quienes aún no han llegado, sostenidos en la dimensión aún no abarcable del porvenir. Por su parte, Fratelli tutti, acentuando el carácter cosmopolita de la fraternidad, una fraternidad universal, se detiene con largueza, con generosidad, en la figura del buen samaritano, figura que no podemos dejar de ver tras la persona del Jesús real de carne y hueso. La encíclica se detiene en el dolor que interpela, en el rostro sufriente que se hace vocación y llamado, allende nacionalismos y eticidades concretas acotados por sus íntimas cercanías. Para decirlo mejor, Fratelli tutti parece inscribirse en ese discurso levinasiano según el cual la epifanía del rostro es un llamado comprensible por todos y por cualquiera, es decir, es un texto sin contexto capaz de suprimir la anonimia, una apelación universal cuya legibilidad (en el dolor, el sufrimiento, la viuda, el pobre y el huérfano) puede ser admitida inequívocamente por los aludidos en esa manifestación interpeladora.

En ambas encíclicas veremos una aspiración universal, una ética cósmica comprometida con la totalidad de la creación y con las deudas generacionales, así como una fraternidad universal que descree de las dimensiones cercanolejano, pues el sufrimiento hace de lo infinitamente lejano algo profundamente cercano. La aspiración, difícil, de ambas es procurar un llamado a la paz entre los hombres, buscando lo que hay de común entre ellos, más que los muros que los separan, ora artificialmente, ora gracias a ideologías arraigadas en el conflicto. Metodológicamente el artículo intentará mantenerse más acá de los límites confesionales, para así extraer la savia propiamente racional de los argumentos. No deseo llamar a esto "ateísmo metodológico" (la expresión es de Habermas), pero sí "prudencia metódica", para, respetando así ambas dimensiones, mantenernos en ésa en que la racionalidad marca las normas del discurso. 


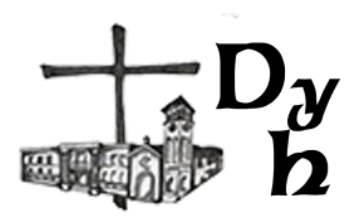

\section{Identidad y diversidad, comunitarismo y cosmópolis}

Digna de abundante loa en esta suerte de profundización de la secularización religiosa es justamente la depuración de la cáscara dogmática, para ir dejando al descubierto la razón inscrita en ella. En otras palabras, lo confesional abre el tenor de su texto sagrado para hablar a una totalidad humana, una y diversa, allende sus propios límites confesionales. Tal vez haya en esta postura doctrinaria absolutamente inclusiva un cosmopolitismo al que ciertos comunitarismos hodiernos hacen ascos, porque siguen tras las líneas aristotélicas y hegelianas que pontifican lamentando la ausencia de calor en comunidades gigantescas, es decir, en comunidades que realiter no lo son. De allí que una comunidad cosmopolita es cualquier cosa menos una comunidad, vale decir, en el cosmopolitismo no existe una encarnación concreta de un pueblo, de un ethos, de un etnos, sino una vaga abstracción sociopolítica sin hondura práctica: la verdadera comunidad, allí donde arraiga el espíritu, es el pueblo, la nación concreta, una osificación palpable del Volksgeist. Sin embargo, hay que preguntarse si la amistad social en la polis es una promesa redimible, ya que la amistad que allí arraiga es una amistad entre hombres, no una amistad que incluye la diversidad de género y de pueblos (¿cómo se puede ser amigo de un siervo, de una mujer, del hombre atado a las actividades manuales/mecánicas?). Si no puede existir amistad entre distintos, entonces la amistad lo es a condición de excluir, lo cual sedimenta un concepto "falogocéntrico de amistad que ha dominado la tradición, y lo define como homosexual y viril..." (Derrida, 1998, p. 170). Ello desencadena un conjunto de particularidades comunitarias que seguramente se enfrentarán mutuamente, a través de la guerra, o de alguna expresión de ésta. De allí que el conjunto de destinos particulares de los diversos espíritus objetivos no puede constituir una historia de paz.

Según Hegel, aquí hay una manifestación de la libertad histórica, en especial del pueblo llamado a prevalecer sobre aquellos que prefieren la mera sobrevivencia a fajarse en un conflicto autoafirmativo. Una resolución, pues, de la libertad en la sustancia del conflicto, resultado de una hostilidad raigal a un cosmopolitisme abstrait et vague (Hyppolite, 1985, p. 53). Curiosamente, las dos últimas encíclicas corren más allá de las fronteras de finitudes cerradas sobre sí mismas, sembrando entonces éstas el conflicto, a fin de que la historia devenga 
y, en ella, la libertad sea constituida. Lo confesional, superando sus propias opacidades, concibe lo lejano y lo cercano como enmarcados por una misma necesidad, o sea, la fuerza interpeladora del sufrimiento. No hay en ellas, por supuesto, un a priori epistémico al modo kantiano, pero sí un a priori patético, el a priori del sufrimiento, un fundamento absoluto a cuyo llamado es casi imposible no prestar atención: pero el fundamento se da, existe, no se autopone, no se auto-determina, porque estamos en el ámbito de la pasividad absoluta. Patético, el a priori llama a minimizar la crueldad, a considerar siempre cercano incluso lo lejano, una universalidad que podríamos calificar de "prelingüística; el sufrimiento tiene lugar por fuera del lenguaje" (Critchley, 1998, p. 59). Por consiguiente, el actus primus es la afección; el actus secundus, el lenguaje, que daría cuenta del prius afectivo, única auto-posición del sujeto, llamada a esclarecer lo que simplemente se da, ocurre, pasa. No únicamente por fuera del lenguaje tienen lugar el sufrimiento, sino incluso por fuera de toda modulación social, ética o étnica, por fuera de un nosotros constituido en la exclusión, más allá de los presuntos destinos particulares de los pueblos, de las comunidades con un origen y un horizonte común, como si la compasión samaritana estuviese en la base de toda atención posible al otro.

\section{Fundamentalismos y contextualismos}

Abiertas desde dentro, las fronteras confesionales acaso abarquen mucho más que los discursos filosóficos à la page que descreen de los registros religiosos al momento de reconfigurar lo social. Encantados por sus prácticas concretas, sus juegos de lenguaje, sus semánticas irrebasables y la reducción de cualquier texto a un contexto determinado, los comunitarismos no acceden a la vaga abstracción universalista fundada en un tono patético, el cual, para aquéllos, no dejaría de ser sino un Ilano objeto melancólico, remedo de una filosofía fundamentalista incapaz de resignarse a la extinción de los dioses. Ciertos custodios de la filosofía piensan que un esfuerzo fundamentador es per se fundamentalista, remedo inútil de los ángeles guardianes que no nos desamparaban durante nuestra culpable minoría de edad. La verdad es que, afirman tales custodios, semejante esfuerzo (no reconocido como tal por los fundamentadores/fundamentalistas) no es sino la retraducción de figuras teológicas ya fenecidas de una vez y para siempre. La filosofía de los actuales 
custodios ya no es susceptible de amistarse con una filosofía custodiada por un pasado deshilachado: hay que alegrarse por las vísperas de un amanecer al que repugnen fundamentos y universalismos que pretendan, inanemente, trascender el lenguaje que somos dentro de un determinado contexto y el uso que le damos en él. La luz tibia y acogedora del contexto desprecia esa, por lo demás, impotencia, pues nos creamos y recreamos al interior de mundos marcados por un lenguaje específico, como si éste fuese insuperable.

Siguiendo la "levedad" de Rorty, podríamos decir que todo argumento, político o no, es dependiente del contexto y no puede escapar de éste. Si se desea convocar a la gente a las propias creencias, sean de la especie que sean, basta con persuadirles de que el marco de valores políticos defendido por personas como Rorty es suficientemente inclusivo, sin postular por ello una fundamentación que dé cuenta de la verdad/veracidad de las creencias que se proponen a los demás. Fundamentación y universalismo no tienen ningún parentesco indispensable con la constitución liberal-democrática explicada en llanos términos contextualistas. Basta con la persuasión, no es menester un derroche argumentativo cuya fuerza interna conduzca al cambio racional, exclusivamente racional, de preferencias en los agentes sociopolíticos (desde luego, esta inicial posición habermasiana ha cambiado con el tiempo: hay que ir allende la levedad rortyana y la ingenuidad habermasiana que sigue pensando lo humano en términos stricto sensu racionales, es decir, como animal racional dotado de lenguaje). Como la persuasión aquí se asimila a la adhesión a valores presuntamente superiores (¿cuál es el canon que determina tal superioridad?), entonces no se toma en cuenta la posibilidad populista-demagógica de que ella sea usada para la manipulación de las masas. Lo reconozcan o no los rortyanos, la superioridad que pregonan no puede quedar empotrada en un conjunto de creencias que son las propias, sin dar alguna razón fundamental para solicitar posibles adhesiones. Se puede persuadir en pro de la democracia, pero también, como hemos visto en los últimos años, en contra de ella, en favor de regímenes de corte autoritario, dados a las elecciones indefinidas de los mandatarios o de los sargentos de turno y proclives a neutralizar per fas et per nefas el estado de derecho incorporado en la vida democrática. 
Da la impresión de que la tiranía contextual impide a los sujetos qué seguir y qué ya no seguir en el seno de una tradición concreta. Defendidas en sus límites, las comunidades lingüísticas y culturales parecen no haber reconocido nuevos modos de integración que trascienden los ocasos en los que aquéllas se desempeñan, modos adscritos a dimensiones globales y al tipo de producción subjetiva que a ellas corresponden. Sacralizadas, las comunidades nos persuaden de que su vida concreta impide a los individuos desprenderse de ellas, de porciones de creencias y prejuicios, o de someter a la acribia de la razón, cuando se dé el caso, creencias y prejuicios que han sido colectivamente problematizados, abriendo entonces esos subtextos a un nuevo tipo de comprensión y a la aceptación de valores, juicios, creencias que antes no podía llevarse a efecto: si ello no acerca a una concepción cosmopolita del mundo humano, entonces la dogmática clausurada de posiciones laicas parece menos integradora que la de ciertas expresiones confesionales. Pero un Estado debe relacionarse con ciudadanos más que con miembros comunitarios, situación extrema la última que, a la postre, "sería el testimonio de un debilitamiento general (...) del Estado nacional" (Touraine, 2005, p. 217). Las libertades públicas se han pensado, constituido y constitucionalizado desde la perspectiva de la ciudadanía, no desde la óptica de un conjunto de limitaciones comunitarias con mayor relevancia que el cuerpo legal del Estado, mediando un conjunto de "restricciones internas" (lo permitido y lo vedado) impuestas por los dirigentes comunitarios a los miembros sometidos a su autoridad, sea laica, sea religiosa. Es por ello que el "comunitarismo se ha definido por oposición a la ciudadanía (...), el comunitarismo es un ataque evidente a las libertades individuales" (Touraine, 2005, p. 183), ya que ciertos derechos colectivos se imponen sobre el ethos liberal del Estado.

\section{Samaria}

En resumen, no se trata de optar o por el Estado o por la fragmentación comunitaria, sino de, llegados al extremo, colocar en situación de diálogo las fronteras inevitablemente aproximadas; así como el propio lenguaje es la condición de posibilidad de adentrarnos en otro lenguaje y en la cultura incrustada en él, asimismo, la propia tradición es la condición de la que se parte para propiciar un encuentro con otra diferente, estableciendo lo que se ha 
llamado una fusión de horizontes, una reestructuración de mayor complejidad capaz de poner en cuestión lo que por tradición se tenía por bueno. Pero esta fusión no es más que descentramiento y des-absolutización de la autocomprensión de cada eticidad y ensanchamiento de los límites de cada ethos que se encuentra allí donde las fronteras se hacen porosas, no ásperos muros de enhiesta solidez que impiden la palabra de quienes avecinan sus lenguajes y sus acervos. Los cierres lingüísticos pierden su inmaculada ingenuidad al tratar con juegos de lenguaje diferentes: se descolocan y recolocan, se descentran y recentran, llevando consigo la visión de mundo proveniente de otras fronteras. Además, ningún muro es lo suficientemente inexpugnable como para no ser salvado, tanto por propios como por extraños. En suma, la serenidad (¿o el temor a los extraños?) de las estrechas puertas comunitarias no se aviene con una compasión que abre puertas y tiende puentes, que ve en la herida una interpelación y en la epifanía del rostro que habla allende cualquier lenguaje (Levinas), una súplica de la cual es menester responsabilizarse, pero sin la voluntaria y deliberada decisión de hacerlo, puesto que el sujeto se define menos por una modernidad controladora que por una kenosis de su propia egología.

Laudato si' es una hermenéutica que de forma crítico-reflexiva aborda la unicidad de un modelo de desarrollo. La encíclica se asoma a las falsas certezas de un desarrollismo frío y a las devociones abstractas de una razón instrumental desprovista de horizonte sapiencial. Como en todo tono profético, se denuncia el presente desde el presente, por las catástrofes que él mismo va gestando desde sí, rompe con la seguridad altanera de devociones tecnocráticas, indicando ciertas formas de orden: que la economía esté al servicio del hombre, no al revés, que el hombre no es dueño y amo de la naturaleza en el sentido de ejercer sobre ella un uso y abuso descomedido, destruyéndose justamente así el legado de las generaciones futuras. Si existe orden, por añadidura existirán lógicas respetuosas de los seres humanos, del ambiente, del bien común. Si existe orden, la peligrosa concupiscencia cae de su trono y el hombre se ordena en sus mociones, tanto personales como sociales. La actual expansión científicotécnica, medio para alcanzar fines más elevados, olvida su condición de medianera, absolutiza sus prácticas, borra su rol, extirpa el orden de los fines. Desde un punto de vista cristiano, la vida sigue una estructura de fines, uno más 
elevado que el otro, de modo tal que algunos son parciales con respecto a otros, es decir, son medios de los más elevados. La cooperación de lo humano con lo divino, empero, puede ser tergiversada en virtud de un desorden antropológico siempre posible, o sea, la compleción de la obra divina es llamada a ser subvertida en la arrogancia humana que desordena medios y fines ${ }^{1}$ : el hombre y sus productos se colocan como culmen y remate de lo creado, y el ius utendi et abutendi se confirma como la relación que mantendrá con el ser. Pero la fragilidad es la esencia misma del ser creado (De Benedetti, 2005, p. 74), pues nosotros mismos, como afirmaba Adorno, somos un fragmento de la naturaleza, por ende, no podemos advertir, sub specie hominis, lo que se deriva de un uso imprudente, monológico y despolitizado de un poder que no tiene dentro de sí ni límites éticos ni, por supuesto, teológicos.

Los riesgos son globales, siguiendo a Beck (1998, passim), pues las consecuencias del desarrollo tecnológico no respetan ni límites ni fronteras, ni el capital puede ser refrenado ya por un débil Estado nacional. La deslocalización capitalista actúa desarraigadamente, importándole poco el ethos donde asienta sus prácticas. Dice la encíclica: hay empresas "que hacen en los países menos desarrollados lo que no pueden hacer en los países que les aportan capital" (Francisco l, 2015), generando entonces pasivos ambientales y humanos, residuos de una actividad localizada allí donde el poder de negociación suele ser escaso. La carta nos conduce a esas dimensiones de la existencia tomadas por las semánticas sistémicas. Es explícito el texto a este respecto, pues nuestras actitudes reducidas a la dominación o al consumo deberían recordar esos otros aspectos que no pueden ser concebidos como un saber efectivo, el saber concreto que hoy solapa las demás dimensiones de la existencia: la belleza nos llama e interpela, el asombro nos solicita, la mística ante los espacios infinitos fortalece nuestro estupor, el límite de nosotros

\footnotetext{
${ }^{1}$ Lesión personal y colectiva puede ser el fruto del desorden antropológico y del dominio de las pasiones. La avaricia, una pasión recursivamente encerrada en sí misma, tiende, tal como escribía Aristóteles en su Política, eis apeiron, al infinito; l'uomo avaro è guidato da un desiderio innaturale che non conoce fine (...) Una simile brama di ricchezza smodata e viziosa, non solo in quanto offre l'opportunità di perpetrare tutti $i$ vizi associati alla ricchezza a all'amore per essa, ma anche perchè fa dell'uomo uno schiavo della ricchezza invece che il suo padrone (Langholm, 2007). Traduzco: El hombre avaro está guiado por un deseo innatural que no conoce fin (...). Un ansia de riqueza desenfrenada y viciosa, no sólo en cuanto ofrece la oportunidad de perpetrar todos los vicios asociados a la riqueza y al amor por ella, sino también porque hace del hombre un esclavo de la riqueza en vez de su señor.
} 
mismos, que podemos llamar Dios, no termina de morir, a pesar de tanta religión atea haciendo propaganda en este sentido. Las preguntas se empobrecen, los discursos agotan en sí el panorama propio de grandes inquietudes: por qué vivir en medio de grises, mengua de los verdes, por qué la diversidad tendría que dar paso a una imbecillitas homogénea, construida de caprichos importados, de tranquilidades artificiales y de descartes brutales que incluyen la instrumentalización y desecho de los embriones vivos. Es la "lógica del usa y tira" (Francisco I, 2015), incapaz de reconocer y de admitir dignidad en la naturaleza, mientras que la vida de los nonatos queda adherida a un discurso feminista absolutizado (un cuerpo que es completa propiedad privada y autoclausura, incapaz de admitir en sí los argumentos de ese otro implicado genéticamente en la persona, en potencia, del nonato) que propugna el aborto sin mayores cargos de conciencia. No existe en este tipo de discurso un otro, sino solamente un sí mismo. Una sologamia, una autogamia, aunque ello constituya una contradictio in terminis. $Y$ si existiere, la primacía del sí mismo posee tal talante que la voz del otro no debe ni siquiera imaginarse. El otro aparece, así, como un epifenómeno del sí mismo, como un accidente fácilmente remediable, como la noche de unos amantes descuidados.

El control biopolítico ${ }^{2}$ de las poblaciones no significa sino la pérdida de un tipo de socialización nutrida de recursos comunicativos aportados por la

\footnotetext{
${ }^{2}$ En la selva de significados del término "biopolítica", optaremos por el concepto desarrollado por Foucault y luego ampliado por Agamben: "El concepto de la biopolítica remite aquí al desarrollo un conocimiento político específico y a nuevas disciplinas como la estadística, la demografía, la epidemiología y la biología, que analizan los procesos de vida a nivel de la población para «regir» individuos y colectivos con medidas corregidoras, excluyentes, normalizadoras, disciplinarias, terapéuticas u optimizadoras. (...) Siguiendo a Agamben, la separación principal entre «nuda vida», aquella del ser reducido a sus funciones biológicas, y la existencia jurídica ha determinado la historia política de Occidente desde la Antigüedad..." (Lemke, 2017, p. 20). Véase también M. Di Giacomo 2020, p. 7): "Un tema recurrente es la incrustación de la política en la vida, llámesele biopolítica, denomínesele necropolítica, esa forma de construir criterios para permitir vivir o para, sencillamente, dejar morir. Tecnologías del control, de la vigilancia y de la muerte aparecen por doquier, cuya anticipación más explícita se encuentra en el panóptico de la casa penitencial benthamiana, y cuya actualidad exacerbada encontramos hoy en las restricciones jurídicas impuestas globalmente en virtud de una pandemia, (...), descontrolada. La política ha encontrado la coartada de una supresión: los derechos individuales de corte liberal son puestos entre paréntesis a fin de que el Estado nacional y las instancias supranacionales puedan agendar y combatir eficazmente un riesgo global que ha deshecho las fronteras geográficas. Aquí se debate el tema de un sujeto jurídico, pensado a escala cosmopolita, dentro de una hospitalidad cosmopolita, tal como la ideó Kant, y
} 
tradición, renovados por las prácticas cotidianas y revisados por el lenguaje. En el auge del control, lo que menos existe es la autonomía ilustrada y la autorrealización por medio de la política. La "autooptimización técnica" (Habermas, 2002, p. 120) prescinde de la reflexión y de los propios fines. "La cultura del descarte" incluye un factor de obsolescencia que acelera los mercados, centrifuga a los mayores y da escasa importancia al mundo por venir: que mi deseo se realice aquí y ahora, incluso si hay que hipotecar el futuro, parece ser el santo y seña de una voluntad inmoderada. La dermicidad del mundo digital, el redentor de estos tiempos de confinamiento, y la pérdida de la somaticidad del encuentro, contribuyen al "ruido dispersivo de la información" (Francisco I, 2015), a la fragmentación de los significados en la medida en que los datos se hallan desprovistos de contexto, la frivolidad abraza los comentarios acerca de lo noticioso, el narcisismo de quienes no quieren sino opiniones semejantes a las suyas encuentra en la red infinitos puntos de apoyo, perdiéndose en consecuencia una genuina experiencia de alteridad. Añádase a lo anterior la fragilidad recién descubierta en 2020 con el virus globalizado, incitador de políticas de control excluyentes que pueden llegar al extremo de decidir quién debe vivir y quién debe morir, muchas veces como consecuencia del desmantelamiento liberal del Estado benefactor: dentro del manejo eficiente de los recursos es "justificable" descartar por razones de edad o de enfermedad. Así, pues, "Excluir a los ancianos de los cuidados críticos en caso de una pandemia no es una idea nueva. Algunos médicos recomendaron negar la atención crítica a cualquier mayor de 85 años en caso de una pandemia de gripe" (Jarvie, 2020).

\section{Pulchritudo}

Evangelii gaudium habla de la natural disposición humana hacia la belleza. El camino peregrino no deja de estar flanqueado, para el creyente, de señas, signos, sacramentos. En el cristiano, amor, orden, belleza y verdad se coimplican, mostrando la vinculación de las personas divinas. Trinitariamente, el mundo "es una trama de relaciones" (Francisco I, 2013) que el ser humano ha ido apagando poco a poco: unidad y trinidad es el mundo, por eso no se

el tema de un individuo cada vez más restringido en derechos debido a los estados de excepción". 
pueden apresurar lecturas que impidan la religación de cada presencia del ser con otra multitud de presencias. "No matarás" no sólo implica una abstención con respecto al otro, a su derecho a la vida; el precepto corre más allá: "no matarás", dice Levinas, también significa "tú cuidarás del otro", serás responsable de él. Asimismo, preocuparse por la ecología implica una ética del cuidado, por el ambiente mismo y por lo que de él debe ser preservado, en atención a la historia que todavía no se ha cumplido. Es la ley del éxtasis que vive en cada persona, no la del encierro, persona que "sale de sí misma para vivir en comunión con Dios, con los demás y con todas las criaturas" (Francisco I, 2015).

Es el mundo moral el que debería guiar las obras de las technai. La fábrica mundana debería saber por qué y para qué produce con tal desenfreno. Sin embargo, la civilización técnica va suprimiendo todo límite que refrene su dinámica, incapaz como es de reconocer que ella misma podría padecer de esa frase hegeliana conocida como la "furia de la desaparición", o sea, ella misma cae bajo el peso de un discurso unilateral autoabsolutizado. Es la orgía de la lujuria plana del consumo: el valor, todo valor, se somete a la fecundidad del mercado ${ }^{3}$, en cuyo seno toda cosa, evento, dignidad se convierte en tasa, lo cual viene a ser la inteligencia propia de estos tiempos. Sin más y sin menos, el espíritu transita entre los bienes, y si no puede adquirirlos, pues transitará por ellos mediante fórmulas sustitutivas, compensaciones ideológicas, el autoengaño de los infelices, tan infelices como los que amanecen ante las tiendas salvíficas esperando por la llegada de novedosos artilugios (de control, cautividad, manipulación, pues, entre otras cosas, un teléfono celular sirve también para seguir los pasos del orgulloso comprador). En esta una economía global, la administración de lo común ha sufrido un conjunto de reducciones. Dicha reducción tiene por centro el consumo: La persona es un bien de consumo en sí misma, descartada cuando ya no genera un beneficio. Laudato sí es un comentario crítico a un modelo civilizatorio que ha perdido de vista no

\footnotetext{
${ }^{3}$ Es importante destacar que, durante la escolástica tardía, la realización de la justicia se daba dentro del lugar ocupado por la economía, "por tanto como acontecimiento moral" (González, 2007 , p. 7). La misma vida económica estaba sujeta al análisis de las consecuencias de los intercambios de los agentes en el mercado; los agentes económicos se hallarían así incluidos en los lugares de realización de la justicia. Un fin social primaba por encima de la mera acumulación de capital: la lógica demencial del capital perpetra algunos fines sociales, mientras que su fin genuino hoy es multiplicarse a más no poder.
} 
sólo la centralidad antropológica, sino también el orden de unos fines que protegerían tanto el bien común, como el fin trascendente al cual el creyente aspira.

\section{La existencia no se piensa, se consume}

El progreso por el progreso no acepta otro discurso: quien no cae bajo el discurso socialmente aceptado parece haber perdido el tren de la historia. Historia de una embriaguez irreflexiva, la nuestra empobrece la riqueza natural, reduce la multiformidad del ser humano, acorrala las experiencias vitales que están más allá de los aparadores que nos devuelven enriquecida con mercancías nuestra propia imagen. La creación, no obstante, habla desde un orden reticulado en cuyo interior lo que ocurre en una de las partes no dejará de reflejarse en las otras partes y en el todo que las explica y que ellas integran. "Las criaturas están conectadas" (Francisco I, 2015). Lo fundado es una filigrana de relaciones íntimas que pueden ser comprometidas con intervenciones técnicas cada vez más invasivas. De acuerdo con la cultura de la reificación universal, no solamente la naturaleza es objeto de apropiación y de control, también el mismo mundo humano es sometido a esa instrumentalización. Es éste el diagnóstico de la primera Escuela de Frankfurt. Nada queda exento de una apropiación que retira la especificidad de los predicados que competen a cosas y personas entendidas en su singularidad, pasando entonces a ser no más que una pieza de recambio de un mercado autoacelerado, deliberadamente obsolescente, cautivo del frenesí de la reposición novedosa de nuevos artefactos. Una ética cósmica, atenta al porvenir, advierte el flaco favor que el crecimiento por el crecimiento acarrea al entregarnos sin rodeos a la celeridad y obsolescencia de los bienes. Pero para esto, ha dicho la encíclica, hay que renunciar a "convertir la realidad en mero objeto de uso y de dominio" (Francisco I, 2015). A la ansiedad de la renovación mercantil corresponde el ardor de la ansiedad personal que busca, en medio de un consumo demenciado, la paz que allí, por razones obvias, nunca encontrará. No brota la pregunta acerca del telos de esas premuras. Tampoco por qué seríamos soberanos dentro de un juego deseante en el cual existimos, nos movemos y somos. "Pienso, luego existo", ha sido suplantado por "consumo, luego existo" (Cortina, 2004). La dignidad humana se esfuma ante las cláusulas de una 
realidad manejada más por un "mercado divinizado" (Francisco I, 2015) que por la solidaridad. Los intereses del mercado "convertidos en regla absoluta" (Francisco I, 2015) poseen esa dinámica confiscadora de experiencias alternativas. Pensar en los fines de la acción humana, allende lo mercantil, corre el riesgo del ridículo, de inquietud utópica, de falta de sentido de lo real.

\section{Redención de los vínculos creados}

El cuidado de los vínculos frágiles entre las cosas radica en el servir más que en el ser servidos, en el abajamiento más que en el ensoberbecimiento, en la constitución de una antropología integral lanzada a recuperar sus propias desmemorias y a dejar de lado un "antropocentrismo despótico" (Francisco I, 2015) que descuida sus nexos con la creación. La vida es diaconía, oblación. La centralidad de la persona y el primado del bien común han permitido a la Iglesia responder a las ansias privatizadoras que redundan en beneficio de unos pocos. Si la naturaleza es "lugar de la presencia divina" (Francisco I, 2015), al cristiano le parece imposible que el destino común de los bienes (y el ordenamiento ético que supone) se subordine a prácticas privadas que imposibiliten su uso y disfrute colectivo. La función social de la propiedad admite esta subordinación, ya que "la subordinación de la propiedad privada al destino universal de los bienes $y$, por tanto, el derecho universal a su uso es una regla de oro del comportamiento social y el primer principio de todo ordenamiento ético-social" (Francisco I, 2015). Incluso el ambiente es un bien colectivo, cuya usura por parte de unos pocos privilegiados no significaría sino la ruina de muchos, es decir, la negación de la existencia de los demás y la gestación de un clima estructural de pecado.

San Buenaventura dijo de san Francisco en Legenda maior lo que sigue: enseñaba que las casas que edificasen fueran humildes, que no las habitasen como propietarios, sino como inquilinos, considerándose peregrinos y advenedizos, pues constituye norma en los peregrinos ser alojados en casa ajena, anhelar ardientemente la patria y pasar en paz de un lugar a otro (San Buenaventura, 1998). El bien común no está reservado para la inmediatez del presente, sino que ha de referirse a la "solidaridad intergeneracional" (Francisco I, 2015), al mantenimiento de los bienes conferidos, a la entrega a las generaciones futuras de unos bienes de los cuales somos apenas custodios. La 
redefinición del "inmediatismo egoísta actual" (Francisco I, 2015) se precipita hacia las preguntas sapienciales capaces de perfilar una crisis en el modelo actual de consumo. Si rebrotan estas preguntas quizás los fines sean guiados éticamente: "¿Para qué pasamos por este mundo? ¿Por qué vinimos a esta vida? ¿Para qué trabajamos y luchamos? ¿Para qué nos necesita esta tierra?" (Francisco I, 2015). Pero si se da la espalda a semejantes preguntas, ¿no será entonces que el apocalipsis anunciado ya comenzó en el seno de este modelo civilizatorio reduccionista, pero que no se presenta con la espectacularidad de un evento?

La solución residiría en la presión desde debajo de los ciudadanos para que sus gobiernos protejan lo común y controlen los excesos del poder, incluyendo el poder económico; presión de los públicos periféricos, normativamente ordenados y orientados con el propósito de embridar una máquina que por su inmediatez se ha vuelto destructiva. Pero volver las tornas en contra de la inmediatez insensata del presente tendrá lugar sólo si los grandes fines siguen presentes en la mente de los hombres: contenidos afines al humanismo, datos contextualizados, los relatos de la memoria, el cultivo de lo propio en una rememoración comunitaria exenta de purismos y de nativismos cómplices de futuras xenofobias, contenidos hoy periclitados en una chata globalización afín al orden mercantil, más que a la sociedad cosmopolita pensada por Kant, respetuosa de las diferencias entre las naciones. No olvidar la reflexión y la tradición en las preguntas acerca de las intervenciones técnicas implica que "la rentabilidad no puede ser el único criterio a tener en cuenta" (Francisco I, 2015).

\section{Por una ética del cuidado}

La autocomprensión actual, pese a la plural posmodernidad, gesta una ecuación donde libertad y consumo se equilibran. En opinión de Habermas, los "autos" que han caracterizado a la Modernidad fueron adquiriendo un carácter privado, aunque esos "autos" indicaron en sus inicios una revisión reflexiva de las tradiciones y el igualitarismo universalista en derecho y moral. En La necesidad de revisión de la izquierda (Madrid, 1991, pp. 54-55) resume la Modernidad en los conceptos de autoconciencia, autodeterminación o autonomía y autorrealización; pero el sentido del prefijo "auto" "quedó 
distorsionado bajo el signo de un individualismo posesivo y de una subjetividad pura y dura". Es imprescindible restituir a ese "auto" un sentido intersubjetivo, pues nadie por sí solo puede ser libre, autosuficiente y dotado de autoconciencia. Pero al mismo tiempo reconoce las fallas presentes hoy en la autocomprensión de la Modernidad, cercana a un "fundamentalismo del mercado" y al predominio de la razón científico-técnica, ajustada a las necesidades sistémicas. Laudato si' afirma que "tenemos demasiados medios para unos escasos y raquíticos fines" (Francisco I, 2015), medios que suelen olvidar los impactos morales surgidos de su propia eficacia. Según tal lógica, el hoy debe ser gozado tanáticamente, el amor no tiene mañana, al deseo se le ha desecado su sentido de trascendencia. Como toda conversión, la "conversión ecológica" significa una transformación del propio ser y de sus relaciones. No resulta de lo anterior una extrema negación del consumo, sino del privilegio de su absolutización, así como de la forma de trato preferido en las relaciones interpersonales.

Una ética del cuidado, que pone atención a los fines, interpela lo constituido, desnuda nuestras creencias anquilosadas, despierta una angustia sensible ante lo que ayer había hecho caso omiso. Es como si una historia interrumpida por el privilegio del mercado reemprendiese su marcha al religarse con sabidurías venidas de antaño, guardadas, pero adormecidas, en nuestra propia piel. Al escuchar los propios vacíos, las dimensiones obliteradas, las inquietudes forzadas a callar, se provoca que las magias mercantiles se queden en su espacio, sin conquistar los que les son ajenos. La Casa Común redescubre los lazos íntimos del ser, reinstituye la religación en la diferencia, admite el vínculo entre todas las cosas, rompe con el desorden de un discurso único, monótono y mercantil. Se abre a un absoluto mestizaje, a la impureza, desechando todo catarismo ahistórico. Al hacerlo así, el mundo retoma esa amplitud que necesita toda diferencia que sale de lo Uno y a Él retorna. Ahora bien, si el Uno permite el discurso de la diferencia, si la Unidad (para los creyentes, Dios) no ha secado la multiformidad del mundo natural, si el Uno no exige una fusión indiferenciada en él, ¿por qué entonces habríamos de permitírselo a ese califato que nos quiere constituir en un simple bazar global? 


\section{Fraternidad y amistad social: Alteridad en la paz; paz en la alteridad}

En Fratelli tutti la inquietud reposa en una "fraternidad abierta" (Francisco I, 2020), en una sociedad fraterna cosmopolita. Es el respeto de la alteridad, ya que quien se acerca a otro lo hace no para absorberlo en su mundo, sino para ayudarle a ser más él mismo. El amor fraterno indica, pues, la apertura universal, la dimensión de la apertura a los demás. La misericordia divina no se limita a los cercanos, sino a la especie humana en su totalidad. Esta es la misericordia a imitar, justamente como la imitó aquel personaje, aquel "impuro" que conocemos como buen samaritano. Tal vez la impureza es el índice de una dialéctica que permite acoger lo extraño en lo propio, haciéndolo poco a poco algo suyo. Hay que ser samaritano, es decir, impuro, para acercarse a la experiencia de alteridad, oponiéndose a un pacto firmado solamente entre iguales, una alianza que impide la entrada de la diferencia. En Jesús hay algo (¿o bastante?) de esa impureza: el buen samaritano es un modelo a seguir, a seguir en su praxis, no en la abstracción de la teoría, mientras que el agua que solicita Jesús a la samaritana es el emblema de una fraternidad dispuesta a superar límites falsamente establecidos al usar la descalificación como recurso para inhabilitar la voz del otro. A la fraternidad abierta se oponen los siguientes movimientos, caracterizados por querer constituirse a espaldas del dolor y de los rostros de quienes sufren. El compromiso aquí es de palabra y se guarda en la pureza de la palabra, no en la sagrada impureza del acto que lleva consigo una dinámica aperturista: toda apertura rompe con la sopor de sociedades e individuos autocentrados, mientras que la cerrazón existencial implica al hombre en el mundo de muros que ha construido en torno a sí mismo para que el sufrimiento no perturbe las puertas de una conciencia anestesiada, que se quiere anestesiada, alejada del compromiso que significa tomar distancia de las propias comodidades conocidas. La vida no se concibe en el cristianismo como tiempo que pasa, como sucesión de comidas, como segundos que se sustituyen progresivamente, sino como tiempo de encuentro, como si las vidas estuviesen destinadas a un encuentro, signifique éste conflicto, armonía, conflicto y armonía, armonía a pesar del conflicto y viceversa. El tiempo es un quale, no un quantum. No es lejano lo lejano ni deja de ingresar en la fraternidad universal: el samaritano experimenta como su carne la carne que aparentemente era de un otro completamente ajeno a él, demostrando, en el amor, que el sufrimiento 
que interpela, interpela porque la lejanía no cabe en esa afección. Lo que no ha de triunfar son ni el silencio ni la mentira, es decir, ni la falsa reconciliación que deja arrinconado en el olvido partes de nuestra propia historia, personal o colectiva, ni el silencio, incapaz de ventilar justamente aquello que debe ser reconciliado. Se repara en la integridad y en la veracidad o no se hará. Lo silenciado, pugnando por manifestarse, no es sino historia no conciliada, el grito de lo no atendido.

\section{Ley del éxtasis, ley de vínculo y religación}

Salir de sí es prestar atención al otro, pero, in primis, intrapersonalmente, dar oídos a la propia insatisfacción que resulta de una voz nuestra no redimida por nosotros mismos: ese otro en mí, esos otros fuera de mí, concitan una dinámica que devalúa la lógica de la insularidad propia de los organismos virtuales, aun si esa insularidad es una insularidad de muchos. Una "ley de éxtasis" (Francisco I, 2020) fractura el propio egoísmo, nos lanza a la maravilla interpeladora del ser y nos abre al sobresalto de tratar con otras vidas, con otros misterios. Únicamente éstos son capaces de permitirnos el crecimiento propio debido al encuentro, a veces beligerante, con otras diferencias, con la unicidad personal del otro que no puedo suprimir, sometiéndolo a la identidad de mí mismo. No cabe una filosofía digestiva si el respeto es el valor absoluto en la relación con el prójimo. Con sus consensos y sus disensos, la ley del éxtasis nos lleva allende nosotros mismos, entramos en la esfera de la comunicación y de la comunidad, en las cuales lo personal no se anula por las constricciones de los poderosos, de los encumbrados, sino que se acrecienta sin prisa y sin pausa.

Salir de sí mismo significa romper con las redes narcisistas en las cuales el consenso se ha dado de una vez y para siempre y donde cada uno de los interlocutores reitera de continuo la letanía del otro. La autotrascendencia personal exige un poco de cultura peregrina, de desierto, nomadismo y hospitalidad, donde se acoja a quien vaga en sus propias sombras y esté dispuesto a compartirlas durante su estadía con nosotros. Es encuentro de noches oscuras, semejantes y disímiles a la vez, es espacio de acogida bajo una tibia luz que iluminará el éxtasis, del cual no podemos sino salir renovados, cambiados, modificados. La autotrascendencia, so pena de convertirse en autonegación, no puede negarse a la experiencia de dar cabida a la voz, al 
rostro, al cuerpo del otro, así sea que este otro aparezca en principio como remotamente lejano, extraño a nuestra cultura y extranjero con respecto a nuestros gestos. Tal vez mientras más extranjero, más impuro, más samaritano, tanto mejor fructifique la ley del éxtasis y la autotrascendencia que en ella se contiene. La paz buscada no se exime del conflicto, éste se encuentra en sus entrañas, pero está allí para ser superado en una dialéctica de incorporaciones: cada otro incorpora al otro, en argumentos, renuncias, renuencias. Sin embargo, se oponen a la paz cierres absolutos, autocentramientos egoístas, el miedo/temor/terror nativista a lo extraño/extranjero/exiliado. Atendamos a la prognosis papal:

1. Nacionalismos cerrados, los cuales, desde la perspectiva católica, son injustificables, ya que la superioridad técnica de una nación no justifica el abuso basado en la propia superioridad. Al contrario, siguiendo a Pacem in terris, esa superioridad implica una obligación social al servicio de los demás, para que logren, mediando el esfuerzo común, la propia perfección (Juan XXIII, 1963). De no hacerlo así, se abandona la justicia y los reinos no pasarían de ser, como escribió san Agustín, magna latrocinia. El desarme debe llegar a las mismas conciencias (porque la paz no puede darse en la sociedad humana si primero no se da en el interior de cada hombre, si éste no analiza sus mociones interiores, ordenándolas, es decir, si primero no guarda cada uno en sí mismo el orden que Dios ha establecido. A este respecto pregunta San Agustín: ¿Quiere tu alma ser capaz de vencer las pasiones? Que se someta al que está arriba y vencerá al que está abajo; y se hará la paz en ti; una paz verdadera, cierta, ordenada. ¿Cuál es el orden de esta paz? Dios manda sobre el alma; el alma, sobre la carne; no hay orden mejor).

2. Un mercado global que reduce a las personas a la condición de consumidores o de espectadores, esto es, una globalización uniformadora que homogeneiza, domina y expolia, obrando bajo la guía de un solo modelo antropológico, el liberal, que optimiza recursos y juega a una ingenuidad abstracta con respecto a la distribución social de sus propios rendimientos económicos mediando las fórmulas mágicas de "derrame, goteo", efecto cascada, 
teniendo en su base el sujeto privilegiado, el empresario cuyo capital se encuentra deslocalizado. Personas y sociedades son sujetadas al corsé único de un modelo civilizatorio que ya ha demostrado sus profundas falencias civilizatorias, con relación a lo humano y con respecto a la conservación de la Casa Común en que lo humano descansa medianamente de su propio peregrinaje.

3. La ignorancia de la historia, que forja personas vacías, aptas para ser instrumentalizadas para planes deslocalizados. Hay ausencia de contexto para los datos masivamente acumulados, provocando así fusiones de horizontes completamente arbitrarios, despreciando las comunidades de interpretación, dando lugar a abordajes cuasifideístas de los textos, sacros o no, como si un espíritu divino compensara la ausencia de formación al hacer el análisis de los distintos discursos. Además, existen nuevas formas de colonización cultural, que es capaz de reducir la multitud de mediaciones entre hombres y culturas. Mientras menos mediaciones, tanto mayor la represión contenida en los acuerdos presuntamente alcanzados; mientras mayores, tanto menor será el contenido arbitrario de los pactos públicamente aceptados.

4. El vaciamiento de las grandes palabras, convertidas así en significantes vacíos, aptos para recibir cualquier significado: democracia, justicia, libertad se usan como instrumentos de dominio para prolongar la estancia de los poderosos en cargos de gobierno.

5. Ante el agotamiento de los recursos se generan ambientes favorables para la gestación de nuevas guerras, con la excusa radicalizada de la conservatio sui de carácter social, ya que los bienes de otras latitudes se van convirtiendo en el espacio vital de los neocolonizadores (reaparición del Lebensraum).

6. No nacidos, ya inservibles, ancianos, entran en la cultura del descarte, como se lee en Laudato si', y en la lesión de la dignidad humana debido al dominio de un discurso pragmático-utilitario.

7. El aumento de la riqueza no vino al mundo sin una profunda estructura de inequidad distributiva, inequidad que tiende más a aumentar que a disminuir. Prestemos oídos a los siguientes datos de 
Piketty: "el $10 \%$ de los más favorecidos posee el $60 \%$ del patrimonio total y el $50 \%$ de los más pobres tiene menos del 5\%" (Chavagneux, 2014).

8. La moderna esclavitud, el comercio de personas para fines sexuales, por ejemplo, impide que la dignidad de la persona humana sea reconocida, $y$, por ende, tratada como fin y nunca como medio.

9. La xenofobia que resulta de sociedades y culturas obligadas a migrar de sus espacios originarios. Acompañan a la xenofobia propuestas populistas escandalosas que usan el temor endógeno para erigir nuevos muros, convirtiendo en sufragios el temor a lo extraño y diferente. Asimismo, el neopopulismo no escatima fuerzas al momento de movilizar en contra de los exiliados las tendencias más bajas y primitivas que viven en cualquiera de nosotros. El neopopulismo no es formativo, sino que llega a tocar y a estimular los miedos más irracionales de la población supuestamente amenazada por los nuevos colonos ${ }^{4}$.

10. El control constante de la vida -biopolítica- se magnifica con las nuevas tecnologías digitales: como un Dios providente, la Internet de las cosas crea algoritmos únicos para cada individuo que se inserte en la red: cada algoritmo responde a la unicidad de cada preferencia personal. La providencia tecnológica, elaborado el algoritmo, proveerá a cada quien de acuerdo con sus exclusivas preferencias (mercantiles, ante todo).

11. El narcisismo de las redes no consiente una genuina experiencia de alteridad, enriquecedora para cada una de las partes que entablan un acto comunicativo.

12. Tales violencias permiten hablar de una tercera guerra mundial en etapas, señala Francisco.

\footnotetext{
${ }^{4}$ Un nuevo término afín a purezas étnicas, el "nativismo", apunta a una "ideología según la cual, en la definición de Cass Mudde y Cristóbal Rovira Kaltwasser, «en los Estados deberían habitar exclusivamente miembros del grupo nativo (la nación) y de que los elementos no nativos (extranjeros) son una amenaza fundamental para el Estado nación homogéneo». Para el autor, el nativismo es racista y xenófobo". Es nota del traductor. (Piketty, 2019, p. 59).
} 


\section{El verdadero encuentro es el desencuentro: no narcisismo, sino diferencia}

¿Qué hemos perdido y qué podemos ganar al no poder convertir los corazones humanos, al ser incapaces de desarmar la palabra y al perder los gestos hospitalarios, la samaritana misericordia de Dios?

Hemos perdido una forma de comunicación humana somática, hecha de gestos, temblores, insinuaciones, picardías, hemos olvidado el perfume de un cuerpo, la delicadeza de unas manos, el calor de un abrazo, la tersura de una piel, los silencios, la modulación corpórea, todo eso que entra en la comunicación y que no se agota en la mera palabra (Francisco I, 2020). Deseamos una universalidad fraterna que no niegue, en la homogeneización abstracta, la riqueza particular de cada individuo, pueblo, nación, de cada cultura que forma parte del mundo. Si bien la Iglesia afirma el derecho a la propiedad privada, no es enfática en una afirmación inalienable de tal derecho, pues antepone a él el carácter común de los bienes de la tierra (bienes creados) y su uso común. La fraternidad rompe con la exclusividad del origen y destino compartido de los pueblos, pues el exilado, el refugiado, el rostro que viene de fuera, tiene derecho a esos bienes, independientemente de la soberanía popular nacional con la que se enmascaran ciertos egoísmos. Esta consideración aparece en Pacem in terris: los exiliados poseen la dignidad de la persona humana y se les reconocerán los derechos consiguientes, que no se han suprimido por haber sido expulsados de su propia nación (Juan XXIII, 1963).

La misericordia de Dios se convierte en este punto en simple gratuidad, independientemente del "retorno" que puedan ofrecer, en bienes y servicios, esos extranjeros a la economía del país de acogida. La liturgia de la donación inscrita en la fraternidad abierta, en un cosmopolitismo sensible a las diferencias, implica borrar del horizonte de convivencia la lógica del do ut des, la lógica del intercambio, aunque luego ocurran inmensurables intercambios. La necesidad no se regula por una ley, menos por la ley de los intercambios justos o de los tratos mercantiles avalados por el contrato: pacta sunt servanda, sí, pero bajo ciertas condiciones, de las que se exime una necesidad atendida por la liturgia de la donación y de la sobreabundancia con esos rostros que interpelan desde fuera. Pero no hay fuera ni lejos para la fraternidad universal, ya que un rostro en apariencia lejano imprime su cercanía por obra y gracia del sufrimiento. El dolor del exilio posee así sus recipientes humanos, la mano que 
no espera recompensa, la mano que no tiene idea de aquello que la otra lleva a efecto. Llamada por el dar, la sobreabundancia que fructifica en la donación se desentiende del retorno que correspondería a ese dar. No do ut des, sino do, solamente do, desalojando por completo la dimensión devolutiva del des.

Así, el cuidado de lo propio no se rehúsa a una asimilación de lo que en principio aparece como no-propio, teniendo como desenlace un mestizaje del que no escapa ninguna cultura actual o pasada. Los purismos no entran en la lógica de identidades culturales abiertas al enriquecimiento propuesto por esas vertientes que aún no han integrado en su propio acervo. ¿Fronteras? Sí, sin duda, pero porosas, como ocurre con toda frontera. Los límites están allí para ser desbordados y enriquecidos, el hombre mismo es una frontera que cruza fronteras y se nutre de su interminable peregrinaje. Frente a la exclusión y la discriminación se impone la necesidad de crear organizaciones mundiales menos burocratizadas y más eficaces (Francisco I, 2020) (que hoy parecen ser empresas de autoservicio más dadas a las declaraciones pomposas que a la búsqueda firme del bien común), permitiendo encarnar efectivamente la Declaración de los $\mathrm{DDHH}$, documento de carácter universal que reconoce la dignidad de la persona humana, más recordada por violentada que por respetada. En la prédica global de hoy lo que se vislumbra es la astenia práctica de la ONU. Si se la conjurase, se acabaría prontamente con el oprobio de regímenes que han hecho de la vida pública su hacienda privada, del control ciudadano del gobierno un asunto que puede ser judicializado. Como dice Mbembe, tales regímenes han dado su venia a la fragmentación miliciana del territorio nacional, dejando a grupos armados, a veces con la anuencia del Estado, el control de recursos minerales, tanto valiosos como estratégicos. "Economía de milicias" (Mbembe, 2011, p. 62) la denomina el autor camerunés.

La despolitización ya no es sólo consecuencia de la tecnocracia, sino de un conjunto de necesidades elementales no satisfechas. Cuando la vida se reduce a mera sobrevivencia (biopolítica impulsada por los poderosos, mafias y milicias de turno), las demás dimensiones vitales van reduciendo su espacio de influencia, incluyendo ésa que desde los griegos es fundamental para la constitución de una vida buena: la actuación ciudadana en el espacio público. Es difícil lograr la paz en un mundo donde el "amor social" (Francisco I, 2020) y la "caridad social" (Francisco I, 2020) encuentran tantas dificultades. El amor 
imperatus del que hablaba santo Tomás exigiría la creación de una institucionalidad orientada a la justicia y a la solidaridad. No obstante, el mundo abre nuevas trincheras para la guerra, sean las geográficas, sean las virtuales; la salvación se entiende en sentido individual, en la forma del consumo y en la creación de una cultura del descarte que genera basureros humanos y materiales, propios de un desarrollo que no presta atención a una máxima ética intergeneracional, a un imperativo categórico de carácter dialógico: dejar a quienes aún no están algo mejor de lo que la generación presente ha recibido. También aquí hay que ponerse en los pies del otro, del no-nacido, imaginando las razones que expondrían en un diálogo abierto y público, como interlocutores enriquecedores de los argumentos que hoy se sostienen sin tomar demasiado en cuenta tanto las periferias del mundo, así como en las voces todavía mudas, mudas porque no han llegado al mundo a decir su palabra.

\section{Coda o conclusión: Entre la desolación y la esperanza}

En medio de tanta desolación, Laudato si' y Fratelli tutti no se rinden, no desmayan, no abdican, pues quieren confortar, sembrar la amabilidad, cultivar la ética del cuidado, que es una ética concreta, aunque no deje de lado la abstracción principista. A este punto, me siento urgido a referir aquellas palabras que Adorno, postrado en sus últimos días, le dirigió a Habermas: "Sabes, ya sé dónde se originan nuestros juicios de valor más básicos; en la compasión, en nuestro sentimiento del sufrimiento de los demás" (Giddens et al., 1994, p. 126). Hablan proféticamente las encíclicas, sin señalar, no obstante, al sujeto que encarne la praxis profética, martirial o no: ni pueblo, ni proletariado, ni multitud. Hay que cultivar la reconciliación partiendo de la verdad, de la cercanía (nadie es nunca suficientemente lejano, el sufrimiento nutre la projimidad, la compasión alienta nuestro éxtasis), de la revinculación con todo lo creado (la razón instrumental rompe esos vínculos o se pierde avilantada en su propia autosuficiencia técnica dominando la creación, abordando el ente como simple ente, jamás como misterio soportado sobre una incógnita): no existirá genuina reparación si la verdad no impera, si el secretismo es el talante de los tiempos, si a las víctimas no se les ofrece un perdón y la compensación de decir su experiencia de oprobio en la libertad de 
la palabra. Y aunque no haya perdón, aunque las víctimas se rehúsen a perdonar a sus victimarios, asumiendo entonces en sí un pecio intestino de conflicto, sin embargo, lo que menos debe triunfar es el olvido: se perdone o no, las víctimas (y los pueblos) se hacen fuertes en la memoria, de esa manera defienden su identidad colectiva, sin ser cautivos de ella, y protegen sus espacios sin una sacralización desmedida de los mismos. Ni una política de la amnesia ni una política de la impunidad parecen aceptables, en especial para las víctimas. Pero para colocar un punto final al conflicto será inevitable llevar a efecto prácticas prima facie repugnantes, de lo contrario, habrá cada vez más víctimas y victimarios, un espacio cada vez mayor para ejercer una reparación, una historia cada vez más lacerada. "Pero no es posible decretar una «reconciliación general», pretendiendo cerrar por decreto las heridas o cubrir las injusticias con un manto de olvido. ¿Quién se puede arrogar el derecho de perdonar en nombre de los demás?" (Francisco I, 2020). Insistimos, la paz burocrática, aunque choque con nuestras más profundas convicciones, resultará inevitable, aunque ella no obligue a la víctima a conceder el perdón a su victimario.

No obstante, un cierto pragmatismo político se requiere para acabar con conflictos históricos duraderos. Ahora bien, si la víctima no puede procurar el perdón, quedará prisionera de sus propios odios, del tiempo tomado por una fuerza destructiva anquilosada. El perdón permite la movilización de tiempo e historia, pero no se lo puede ni obligar ni apurar. Nada de esto es fácil, la paz no se logra de una vez y para siempre, es un continuum de prácticas que no tienen fin, es "una tarea que no da tregua y exige el compromiso de todos" (Francisco I, 2020). Al reinterpretar la paz perpetua esbozada por Kant, se ha señalado que no hay que hablar tanto de paz perpetua, como si ésta pudiera ser sustantivada, sino de que en ella se da una dinámica adverbial, procesual, una inquietud sin reposo: hacia la paz perpetuamente... (Pereda, 1996).

Para terminar, diremos que al observar el panorama actual no somos optimistas, pues las variables bélicas se multiplican, fomentan y encuentran excusas para tomar la escena mundial, una escena donde se vive "una guerra mundial a pedazos" (Francisco l, 2020), una guerra mundial llamada a usar viejos y nuevos recursos, a saber, a utilizar el mundo virtual como un nuevo método de control y de intervención conflictiva (ciberconflicto) (Medina, 2018, passim), a ocultas, invisiblemente, guerra a la cual la afabilidad del Espíritu Santo parece 
hacer poca mella. Además, la fraternidad universal, una eucaristía no-sectaria, se nos muestra hoy carente de realidad efectiva, al menos desde un punto de vista agnóstico, metodológicamente agnóstico, mientras que la Casa Común se disgrega en la intimidad de un montón de egoísmos, personales y colectivos, hechos al talle de la civilización actual. ¿Hay frutos del Espíritu Santo, anunciados con la palabra griega jrestótes? (Francisco I, 2020). Acaso los haya, pero da la impresión de que las fuerzas tanáticas, organizadas sistémicamente, poco proclives a un nuevo modelo civilizatorio (esto es, ni descarte humano ni descarte material, ni projimidad que no se realice en la lejanía ni interpelación que no sea respondida samaritanamente), llevan por ahora las de ganar, como llevan las de ganar las exigencias mercantiles, a las cuales poco importan las lesiones ambientales y las propuestas altermundialistas. Esperemos, pues, que sobreabunde la Gracia, la misericordia divina, aquí y ahora, justamente donde el pecado, en el polimorfismo perverso de la guerra, no hace sino sobreabundar.

\section{Referencias bibliográficas}

Beck, U. (1998). La sociedad del riesgo. Hacia una nueva modernidad. Barcelona: Paidós.

San Buenaventura (1998). Leyenda mayor de San Francisco. Recuperado en 12 de marzo de 2020. http://www.franciscanos.org/fuentes/lma01.html.

Chavagneux, C., (2014). Hacia un aumento de las desigualdades patrimoniales. Entrevista con Thomas Piketty. En: Alternativas Económicas, (15). Recuperado en 07 de noviembre de 2020. https://alternativaseconomicas.coop/articulo/libros/hacia-un-aumentode-las-desigualdades-patrimoniales

Cortina, A. (2004). Qui, què, per què consumir. En: A. Cortina e I. Carreras (Eds.), Quaderns CJ. Barcelona: CJ.

Critchley, S. (1998). Desconstrucción y pragmatismo: ¿es Derrida un ironista privado o un liberal público? En: C. Mouffe (Comp.), Desconstrucción y pragmatismo (pp. 45-85). Buenos Aires: Paidós.

De Benedetti, P. (2005). Postfazione. En: P. Ricoeur, II male. Una sfida alla filosofia e alla teologia (pp 59-76). Brescia: Morcelliana. 
Derrida, J. (1998). Notas sobre desconstrucción y pragmatismo. En C. Mouffe (Comp.), Desconstrucción y pragmatismo (pp. 151-170). Buenos Aires: Paidós.

Di Giacomo, M. (2020). Cosmópolis vs necrópolis: Entre la razón que fomenta la vida y la razón que la suspende. Caracas: Abediciones UCAB.

Francisco I (2020). Carta encíclica Fratelli tutti del santo padre Francisco sobre la fraternidad y la amistad social. Recuperado el 21 de frebrero de 2021. http://www.vatican.va/content/francesco/es/encyclicals/documents/papa -francesco_20201003_enciclica-fratelli-tutti.html

Francisco I (2015). Carta encíclica Laudato si' del santo padre Francisco sobre el cuidado de la casa común. Recuperado el 01 de febrero de 2021. http://www.vatican.va/content/francesco/es/encyclicals/documents/papa -francesco_20150524_enciclica-laudato-si.html

Francisco I (2013). Exhortación apostólica Evangelii gaudium del santo padre Francisco a los obispos, a los presbíteros y diáconos, a las personas consagradas y a los fieles laicos sobre el anuncio del Evangelio en el mundo actual. Recuperado el 10 de enero de 2021.

http://w2.vatican.va/content/francesco/es/apost_exhortations/documents /papa-francesco_esortazione-ap_20131124_evangelii-gaudium.html

Giddens, A. et al. (1994). Habermas y la modernidad (3a. ed.). Madrid: Cátedra. González F., R. (2007). En torno a la justicia económica. Caracas: UCAB.

Habermas, J. (2002). El futuro de la naturaleza humana. Barcelona: Paidós. Habermas, J. (1991). La necesidad de revisión de la izquierda. Madrid: Tecnos. Hyppolite, J. (1985). Introduction à la philosophie de l'histoire de Hegel. Paris: Éditions du Seuil.

Jarvie, J. (2020). Dilemas éticos en la era del coronavirus: ¿Qué vidas se deben salvar? En: Los Angeles Times, 05 de abril de 2020. Recuperado en 01 de diciembre de 2020. https://www.latimes.com/espanol/eeuu/articulo/2020-04-05/dilemaseticos-en-la-era-del-coronavirus-que-vidas-se-deben-salvar Juan XXIII (1963). Carta encíclica Pacem in terris de su santidad Juan XXIII. Sobre la paz entre todos los pueblos que ha de fundarse en la verdad, la justicia, el amor y la libertad. Recuperado el 17 de noviembre de 2020. 
http://www.vatican.va/content/john-xxiii/es/encyclicals/documents/hf_jxxiii_enc_11041963_pacem.html

Langholm, O. (2007). L'economia in Tommaso d'Aquino. Revista Observaciones Filosóficas, (5). Recuperado en 27 de julio de 2020. http://www.observacionesfilosoficas.net/leconomiaintommaso.html.

Lemke, T. (2017). Introducción a la biopolítica. México: FCE.

Mbembe, A. (2011). Necropolítica, seguido de Sobre el gobierno privado indirecto. España: Melusina.

Medina, M. C. (2018). El ciberconflicto: Nuevos desafíos para el derecho internacional humanitario. Bogotá: Universidad Externado de Colombia.

Pereda, C. (1996). Sobre la consigna: 'hacia la paz, perpetuamente'. En: R. Rodríguez A., J. Muguerza y C. Roldán (Eds.), La paz y el ideal cosmopolita de la llustración. A propósito del bicentenario de Hacia la paz perpetua de Kant (pp. 77-100). Madrid: Tecnos.

Piketty, T. (2019). Capital e ideología. Bogotá: Planeta.

Touraine, A. (2005). Un nuevo paradigma para comprender el mundo de hoy. Barcelona: Paidós. 